\title{
Opinion The significance of private gardens for bird conservation
}

\author{
ANDREW CANNON
}

\section{Introduction}

Most human habitations, apart from those of highly urbanized or nomadic populations, have some kind of surrounding land under the private or shared control of their occupants which can be characterized as a yard or garden. The typical configuration and exploitation of such land varies between cultures but the total amount of land and the resources applied can be quite significant. For example over 10 million hectares are devoted to lawn grass in the United States, consuming more synthetic fertilizer than India uses for all of her crops (Uhl 1998). In such affluent societies, leisure gardens have traditionally been ornaments, status symbols, hobbies, even art forms or expressions of spirituality but as general conservation awareness increases, a growing number of these plots are being managed to some extent as wildlife havens by gardeners hungry for information and practical support. I suggest that private gardens are already of significant value as wild bird habitat and that this trend for further enhancement of their wildlife value can be productively exploited for the benefit of bird conservation both locally and generally.

\section{Are private gardens relevant to global bird conservation?}

What is the real global conservation value of a British suburban garden, with its neat little lawns, nut feeders and nestboxes? In my garden, fledgling Blue Tits Parus caeruleus, a species of no conservation concern, are busy devouring expensive imported peanuts whose production occupied prime agricultural land in a poor country. Pure entertainment, a sentimental luxury. On my patio is a table made of Vietnamese hardwood which could have been logged from precious Imperial Pheasant Lophura imperialis habitat (it was a gift!) and many of the plants and trees are exotic species, hosting few of the invertebrates needed to support a sustainable bird community. Historically the typical British garden, prioritizing recreation and the decorative display of botanical curiosities, exploitative and ecologically depauperate, has been a simulacrum, a hyper-reality imposed upon and substantially divorced from surrounding natural ecosystems. It is also a model to which many affluent communities under European influence have aspired in creating and managing their private gardens in the non-European countries where Important Bird Areas (IBAs) and endemism are concentrated, 
further distancing their ecology from that of indigenous wild habitats and perhaps limiting their conservation relevance for native species.

Habitat loss and alteration is the most significant problem affecting threatened birds (Collar et al. 1994) whereas in general the species tolerating the distorted ecosystems of European-style gardens tend to be those most able to adapt to habitat variation and hence least in danger. For example, although garden bird feeding is very popular in Australia, European-style gardens are very different from native bushland habitat. Feeding seems to favour introduced species, helping only the most versatile and mobile natives such as the larger parrots and so not necessarily supporting endangered birds. Indeed it may harm threatened native birds, by promoting the more adaptable introductions at their expense one of the vital questions Birds Australia's new Birds in Backyards project will investigate. Generally the more conservation-minded and knowledgeable individuals in Australia do not feed their garden birds (A. Saunders 1999 in litt.).

Furthermore the concept of the private garden perhaps exemplifies the north/ south dichotomy in human lifestyles, implying as it does the availability of surplus time and money for leisure gardening and for feeding wild birds. As Lois Jammes of Armonia kindly reminded me (1999 in litt.), I live in "another world" from bird conservationists in small countries with developing economies, especially those without a tradition of sentimental or spiritual concern for wild creatures. In many parts of the world European-style gardens are largely irrelevant, unrecognized by indigenous cultures. For example the majority of Zambians sensibly consider vegetation to be more dangerous than decorative as it harbours snakes and scorpions. Most rural Zambian houses are surrounded by completely bare and well-swept ground for several metres on all sides (P. Leonard 1999 in litt.). Despite this local preference for "ungardening", the Zambian Ornithological Society (ZOS) has successfully published a Common Birds of Zambia book, covering the species which tolerate arable and degraded habitats and hence are commonly encountered around villages.

In highly urbanized Singapore, very few citizens have a yard and most of these are concreted or tiled. Yet the Nature Society, Singapore (NSS) still considers it well worthwhile to provide information on wildlife gardening, even to apartment dwellers who may have sunbirds Nectariniidae nesting in their balcony bougainvilleas. And the very few private gardens remaining in Singapore shelter birds formerly common there but now disappearing such as the Magpie Robin Copsychus saularis (L. K. Keang in litt. 1999). Even in Zambia, the gardens of affluent citizens in large towns and around farms are of ornithological interest and many of their owners actively care for species such as waxbills Estreldidae. We know that sustainable conservation can only succeed with community involvement at all levels but nonetheless fostering a love of birds among privileged elites must be no bad thing. And even for those with no garden of their own, or whose gardens must pay their way by providing food, information about "common or garden" birds is still a useful tool for engaging interest. Gardens form the primary interface to the natural environment for the very young (and for the very old), providing many people's first exposure to simple ecological relationships and to personal observations of wild birds. I suggest that despite their ecological limitations, the conservation significance of private gardens greatly outweighs their absolute value as bird habitat. They have immense poten- 
tial to educate and engage their users in concepts of species protection and habitat management, via the entertainment and satisfaction they gain from helping common birds. To an activist confronting bulldozers in a vital IBA, feeding peanuts to sparrows in a suburban backyard must seem like only playing at conservation. Yet playing can be the source of our most powerful and persistent learning. And in the developed north at least, the relative importance of gardens as genuine havens of biodiversity is increasing as rural habitats are continually pressurized by industrial agriculture and urban expansion.

\section{The direct conservation value of gardens: habitats and havens}

The fact is, in modern Britain my own garden is not a discrete ecological aberrance implanted within an otherwise uncompromised natural ecosystem but part of a continuum of modified habitats. The corner of England in which I live has been quite densely inhabited and cropped for more than a thousand years and now almost entirely lacks truly natural wild bird habitat. And my garden birds are not just visiting for emergency food in hard weather, many are resident yearround, establishing territories and breeding productively. In the well-established suburban gardens of London and other cities, birds such as the Common Blackbird Turdus merula, "Amber Listed" as of medium conservation concern (Gibbons et al. 1996), maintain consistent patterns of relatively small and stable breeding territories; a sure sign of good quality habitat (e.g. Simms 1978). In a recent survey of the habitats used by the Song Thrush Turdus philomelos (a Red List species of high conservation concern) in south-east England gardens held $71.5 \%$ of the territories found even though this habitat made up only $2 \%$ of the total area (Mason 1998). Further research in an urban-rural interface suggests that in much of England, farmland may be virtually irrelevant in the conservation. of the Common Blackbird, Song Thrush and Mistle Thrush Turdus viscivorus, the majority of territories being in the "built" environment (C. F. Mason 1999 in litt.). As a proportion of U.K. land cover urbanization, much of it medium-density and characterized by many small gardens, is second only to farmland, which is itself an intensively exploited and rapidly deteriorating habitat. So for an important fraction of our wild bird populations, gardens and parks may be as good as it gets.

Furthermore the model garden is evolving as native plants, wildlife-friendly features and even the tolerance of natural ecological successions become not just acceptable but positively fashionable. The Natural History Museum (NHM) in central London opened a wildlife garden in 1995, billed as "the NHM's first living exhibition" and partly intended as a demonstration for gardeners keen to create quasi-natural habitats at home. By 1998, seven bird species were breeding and more can be expected as the habitat becomes established. My typical English garden now has a wildlife pond, quasi-natural "habitat heaps" and a former lawn now reverting to tussocky meadow, teeming with invertebrates. Our gardens are becoming a progressively more significant segment of the remaining viable bird habitat both in terms of absolute area and relative resource densities. This is partly due to the progressive occupation of so-called waste ground and marginal agricultural land by housing and other development but is also a reflection of the continuing rapid ecological deterioration of our rural bird hab- 
itats as modern "industrial" agriculture sweeps aside traditional cycles and practices and makes our increasingly "natural" gardens look ever more bird-friendly in comparison.

Referring to the British Red and Amber Data Lists for birds of conservation concern (Gibbons et al. 1996) reveals that as well as birds such as Blue Tits, European Robins Erithacus rubecula and Chaffinches Fringilla coelebs, which currently have steady or increasing populations (Crick et al. 1998), my garden can support Red List species of high conservation concern, such as Song Thrush, Common Bullfinch Pyrrhula pyrrhula, Eurasian Tree Sparrow Passer montanus and Spotted Flycatcher Muscicapa striata. Amber-listed species of medium concern resident and breeding successfully in my typical garden might well include Stock Pigeon Columba oenas, Hedge Accentor Prunella modularis, Common Redstart Phoenicurus phoenicurus, Common Blackbird and (this listing surprises many garden birdwatchers!) Common Starling Sturnus vulgaris. So the typical British garden really can provide effective refuge for bird species of conservation significance and this is also the case in several other countries worldwide. In Chile, for example, UNORCH consider urban gardens very important in preserving birds, especially in the arid north where they provide practically the only vegetation and water and in the central area of the country where destruction of natural habitats has transformed gardens into important refuges (G. Egli 1999 in litt.). In Bulgaria the White Stork Ciconia ciconia is strongly associated with homes and gardens and of conservation concern due to a 30\% decline in the past 15 years B. Barov 1999 in litt.). In Sweden several uncommon woodpeckers visit garden feeders Sveriges Ornitologiska Forening (SOF 1999 in litt.). Red List species using gardens in the Czech Republic include Common Nightingale Luscinia megarhynchos, Common Redpoll Carduelis flammea and Common Rosefinch Carpodacus erythrinus (K. Stastny 1999 in litt.).

\section{The indirect conservation value of gardens: engagement and empowerment}

In 1897, an eight-year-old schoolboy called H. G. Alexander noted down the first bird record of his subsequent 70 -year contribution to ornithological monitoring: a Chiffchaff Phylloscopus collybita in his uncle's garden (Alexander 1974). A century later, bird enthusiasts continue to "graduate" into ornithology or conservation from a childhood interest in garden birds. Do we ourselves constitute an important manifestation of their conservation significance? With increasing urbanization, progressively fewer children have the luxury of convenient access to countryside that was enjoyed by the young Alexander brothers, so in fact garden birds may provide their only opportunities for regular observation of any kind of wild creatures. Based on our own personal experiences, we in the north tend to assume that promoting this interest should successfully recruit further support for conservation. Has this approach been effective? In the U.K., the Young Ornithologists Club's annual Big Garden BirdWatch has thousands of children recording the birds seen in their garden over a few hours of a designated weekend. This project generates useful publicity and recruitment for the Royal Society for the Protection of Birds' (RSPB) thriving childrens' section. In fact the RSPB consider garden birds sufficiently important to send an information-rich 32-page colour booklet free of charge to even the most casual enquirers - as long as they 
provide in exchange a name and address for future mailings! The free availability of this high-quality resource, which contains identification paintings of over 50 garden species, is widely promoted in advertising. Even the paper bags in which goods purchased at reserves are packed carry an application form for this booklet. Garden birds have been productive for the RSPB in terms of name gathering, recruitment and fostering a wider appreciation of conservation but of course an active interest in both birds and gardens is extremely widespread in the U.K. BirdLife partners in other countries such as Norway, Denmark, the Netherlands and Bulgaria also provide information on helping garden birds to members and enquirers but with mixed success in terms of measurable recruitment. Even so, this is generally viewed as effective use of resources, especially in countries with marked seasonality where feeding birds in winter is a popular humane response to cold weather.

Embedded in the sociocultural subtext of the European-style private garden are urges to collect, catalogue and curate. If we can direct this energy towards birds we add another dimension to gardeners' ornithological involvement and commitment to conservation. Two main approaches have been tried. Firstly, sup porting gardeners who choose to configure their plots unconventionally for the benefit of birds and wildlife can be of value where some conformity in garden management is expected or even imposed. In France, the successful Refuges LPO scheme enables garden owners to designate their plots as jardins d'oiseaux and contributes to its own running costs through a participants' registration fee. In a country where in some areas legal rights of access allow hunters to pursue birds onto private land, installing a Refuge LPO sign in your front yard can be a significant and even brave act. The Ligue pour la Protection des Oiseaux (LPO) actively propagates the Refuges philosophy by encouraging participants to organize bird garden "open days" for their friends and neighbours. So the total benefit for bird conservation is much greater than might be expected from the relatively small number of sites involved, about 2500, due to proactive management by LPO and high cultural impact (A. Delporte 1999 in litt.). The National Wildlife Federation of the U.S.A. has enrolled over 22,000 participants into the Backyard Wildlife Habitat ${ }^{\mathrm{TM}}$ programme, despite a $\$ 15$ certification fee (and another $\$ 22$ for the plaque) and there are a number of similar state-based schemes.

Second, enlisting gardeners to record birds systematically (both for their own interest and ideally also with genuine research and ecological monitoring outputs) has been tried in several countries. I believe that the value of garden bird monitoring is significant and increasing, both in terms of the ornithological outputs and the indirect benefits to individuals, communities and conservation generally. Apart from anything else, gardens are highly accessible. Volunteers need not even leave their homes to provide long-term data in large enough volumes to give good sample sizes and to facilitate subsampling and internal controls. It is also generally reliable data as the range of species tends to be limited and confined to those already familiar to most observers and because the data is literally on the doorstep it can be logged at a much higher frequency than a remote study site could be sampled. Weekly records are generally available without excessive volunteer loadings and these enable garden surveys to document seasonal movements and irruptions in fascinating detail over wide areas. Range changes such as the slow movement of the Wood Nuthatch Sitta europaea north- 
wards into Scotland will show up, as will the progress of invasive and introduced species such as the Eurasian Collared Dove Streptopelia decaocto in the U.S.A. In addition, garden data can elucidate trends such as a steady increase in wintering Accipiters in North America or a decline in House Sparrows Passer domesticus in Britain - this latter development underlining the key point that even the commonest birds need monitoring and that gardens may be as good a place as any to do this important work, especially for commensal species. When details of the garden and of artificial resources provided are recorded as well, garden bird surveys can identify habitat features or foods which attract particular species, especially those of conservation concern. Management advice can be fed back to gardeners and conservation-orientated provisioning developments can be trialled and promoted.

As garden ownership is a common aspiration and interest in the U.K. and because special expertise or experience is not required, we have found that this type of survey can be socially and educationally inclusive, albeit inevitably biased towards the more economically established segments of the population most likely to have access to a garden, such as middle income families and seniors. Monitoring garden birds helps to foster a strong sense of environmental stewardship that tends subsequently to extend into the community and further. Recording improvements in their garden's wildlife value is particularly appreciated by the elderly or infirm who can no longer manage their gardens in the traditional way and might otherwise consider their reversion to a semi-natural condition as negative and depressing. There is a genuine Public Understanding of Science pay-off with volunteers directly exposed to the practicalities of ecological monitoring and experiencing a genuine sense of participation. Garden bird surveyors learn more about birds, they have fun and they propagate their learning and the project itself among friends, family and neighbours.

The British Trust for Ornithology's (BTO) winter Garden Bird Feeding Survey (GBFS) started in 1970. It only involves 250 gardeners, most of whom are already dedicated BTO members, but has been run for the past 29 winters producing a simple but unique dataset whose value increases exponentially with each subsequent winter's recording. Our only continuous systematic records of House Sparrow Passer domesticus numbers over a period of sudden but otherwise unrecorded population decline come from the GBFS as this species was largely ignored by our more "scientific" surveys. But running a garden bird survey on any larger scale than this becomes expensive; the costs and benefits need to be carefully evaluated. In Norway feeding birds in winter is very popular but so far Norsk Ornitologisk Forening (NOF) experience a very low level of conversion from participation in winter garden bird surveys to membership of the society (I. J. Øien 1999 in litt.). In Denmark about 10,000 gardeners took part in a garden survey between 1992 and 1996. That project stopped in 1996 as its running costs were not justified by the low recruitment rate to Dansk Ornitologisk Forening (DOF) membership. More than 1,500 of the volunteers did enrol but most of these became associate rather than full members and were only retained for a year or two (B. Johansen 1999 in litt.).

Meanwhile in North America, Long Point Bird Observatory's Ontario Bird Feeder Survey, launched in 1976, had evolved into something rather special. By imaginatively joining forces with Cornell University's Laboratory of Ornithology 
and relaunching the survey as Project FeederWatch over 4,00o volunteers were recruited. Now over 13,000 take part each winter in what has become the largest and longest-established of Cornell's "Citizen Science" programmes, in partnership with the National Audubon Society and the Canadian Nature Federation as well as Bird Studies Canada. Project FeederWatch is forging ahead with on-line data entry via the Internet which enables extraordinary near-real time analysis and display of large-scale bird movements and the project has already produced a roster of fascinating papers (e.g. Wells et al. 1997). But one particular feature of Project FeederWatch had the rest of us, particularly here at the BTO with our 66-year tradition of volunteer bird monitoring, eyeing it with great interest. As well as submitting data, volunteers actually pay a $\$ 15$ annual contribution to the project's running costs. Could this ever work in Europe, with our contrasting tradition of top-down survey funding?

Eventually, the BTO/CJ Garden BirdWatch was launched in 1995, relying on the same bottom-up funding mechanism. To our great delight we now have over 11,000 volunteers recording their garden birds all year round - arguably the world's largest continuous ecological monitoring project with a historical dataset of more than 50 million observer decisions. And yes, they pay us! An annual volunteer's contribution of $£_{10}$ covers the costs of Garden BirdWatch including a quarterly feedback magazine and the machine-readable survey forms which make a survey on this scale feasible. Most new recruits to the survey are not BTO members but many subsequently join, especially once they have committed to a second year of recording. However the BTO is not, of course, a campaigning, reserve-owning BirdLife Partner but an independent ornithological research trust. The majority of Garden BirdWatch recruits are already members of U.K. BirdLife Partner the RSPB. Based on this and the Nordic experience, it seems that although practical involvement in a garden survey works admirably in gaining a second level commitment from the public, for most volunteers it does not necessarily stimulate BirdLife Partner membership in the first place. But it certainly generates unique and fascinating data and, especially if adequately resourced to provide informative and enabling feedback 'materials, it can reinforce and sustain commitment to bird conservation and ecological monitoring.

Eventually, Garden BirdWatch will make two major contributions to the BTO's overall programme. Although the survey design and data collected are deliberately simplified to maximize participation and hence will not tell us much about absolute populations, comparing long-term trends between species will contribute greatly to our knowledge of relative change in this increasingly important habitat. And by comparison of long-term data with trends from other surveys such as the BTO/INCC/RSPB Breeding Bird Survey and with Constant Effort Sites ringing data we will learn much more about how the numbers of birds that use gardens relate to their overall populations and conservation status, relationships which are currently rather obscure and may be highly variable between species. Already, Garden Birdwatch is providing fascinating phenological information, some of which is of particular conservation interest. For example the Yellowhammer Emberiza citrinella is a declining species once typical of our lowland farms but now the subject of a "High BTO Alert" as its population has recently declined faster than any other of our granivorous passerines (Crick et al. 1998). It has been suggested (Bradbury and Stoate in press) that on modern intensive farms, a food 


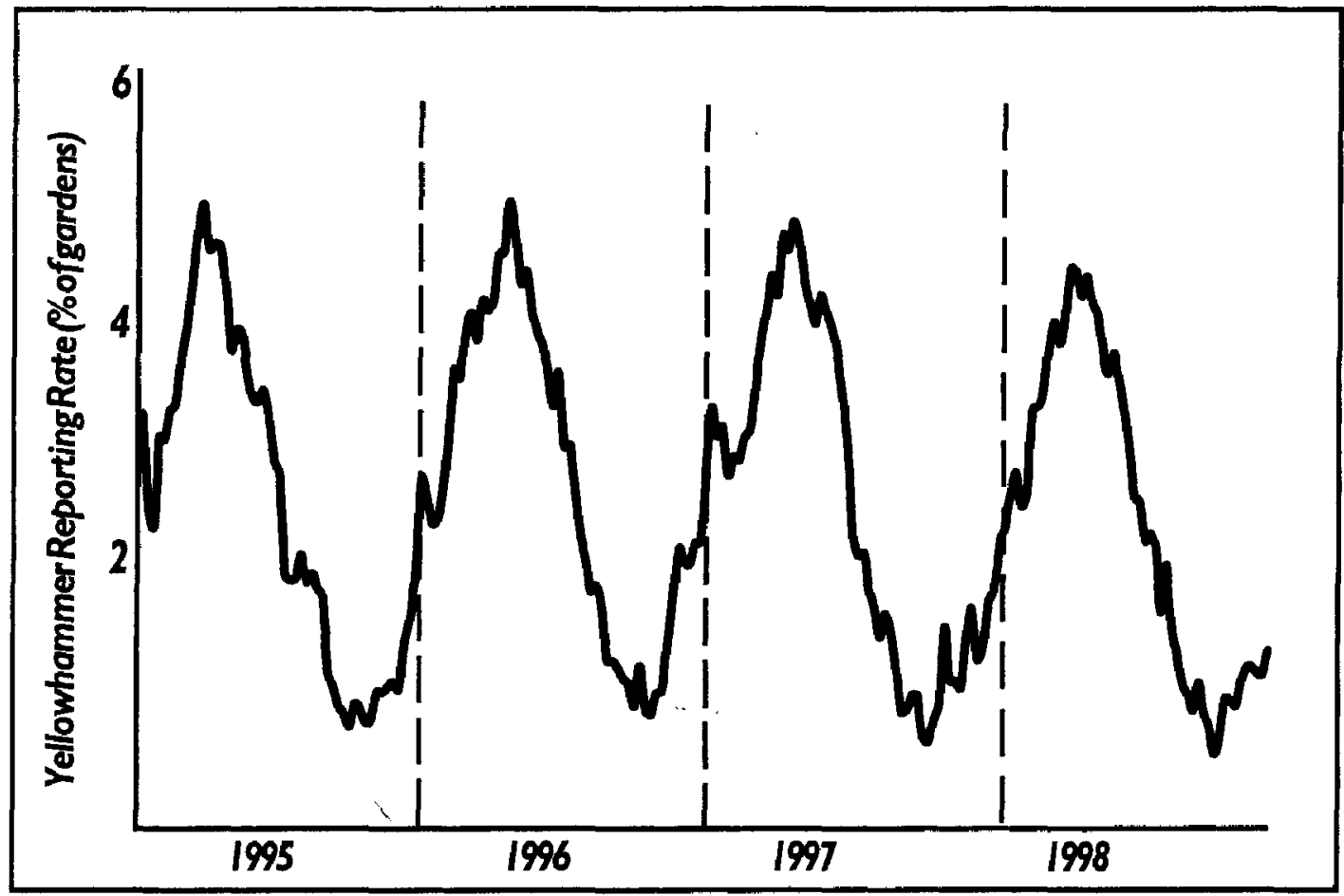

Figure 1. BTO/CJ Garden BirdWatch reporting rate plot for Yellowhammer Emberiza citrinella. This farmland granivore visits relatively few gardens but in each of the four years 1995-1998 a regular peak in their use of this habitat during late spring can be seen.

shortage in late spring is compromising their breeding performance. Garden Bir$d$ Watch data (Figure 1) show a clear peak in the garden reporting rate for Yellowhammer in late spring, providing supporting evidence that this bird is particularly hungry at that time of the year. Garden reporting rate plots can also contribute in a very direct way to conservation and control debates. For example, calls for suburban populations of the Black-billed Magpie Pica pica to be destroyed appear regularly in the U.K. press, on the grounds of reported recent increases in their numbers and perceived excessive predation on nesting songbirds. But the Garden BirdWatch data (Figure 2) show that only about half our volunteers see a Magpie at all throughout the year and there is no clear evidence of a continuing dramatic increase in garden reporting rate. This is a valuable and interesting quantitative contribution to a sometimes heated and value-laden debate with wide implications for bird protection policy.

We should not forget that in addition to large-scale monitoring, gardens can be a conducive arena for other types of ornithology, both amateur and professional. Garden ringing is particularly productive in monitoring the relative annual abundance and movements of seasonal visitors and in enabling behavioural studies. Large numbers of birds can be marked relatively easily and over a wide area, facilitating the analysis of large-scale, long-term movement patterns in species like the European Greenfinch Carduelis chloris (Main 1996) In the early days of a pioneering and influential career in ornithology, the late Dr Frances Hamerstrom obtained her master's degree with a thesis on dominance behaviour in a backyard population of colour-marked Black-capped Chickadees Parus atricapillus 


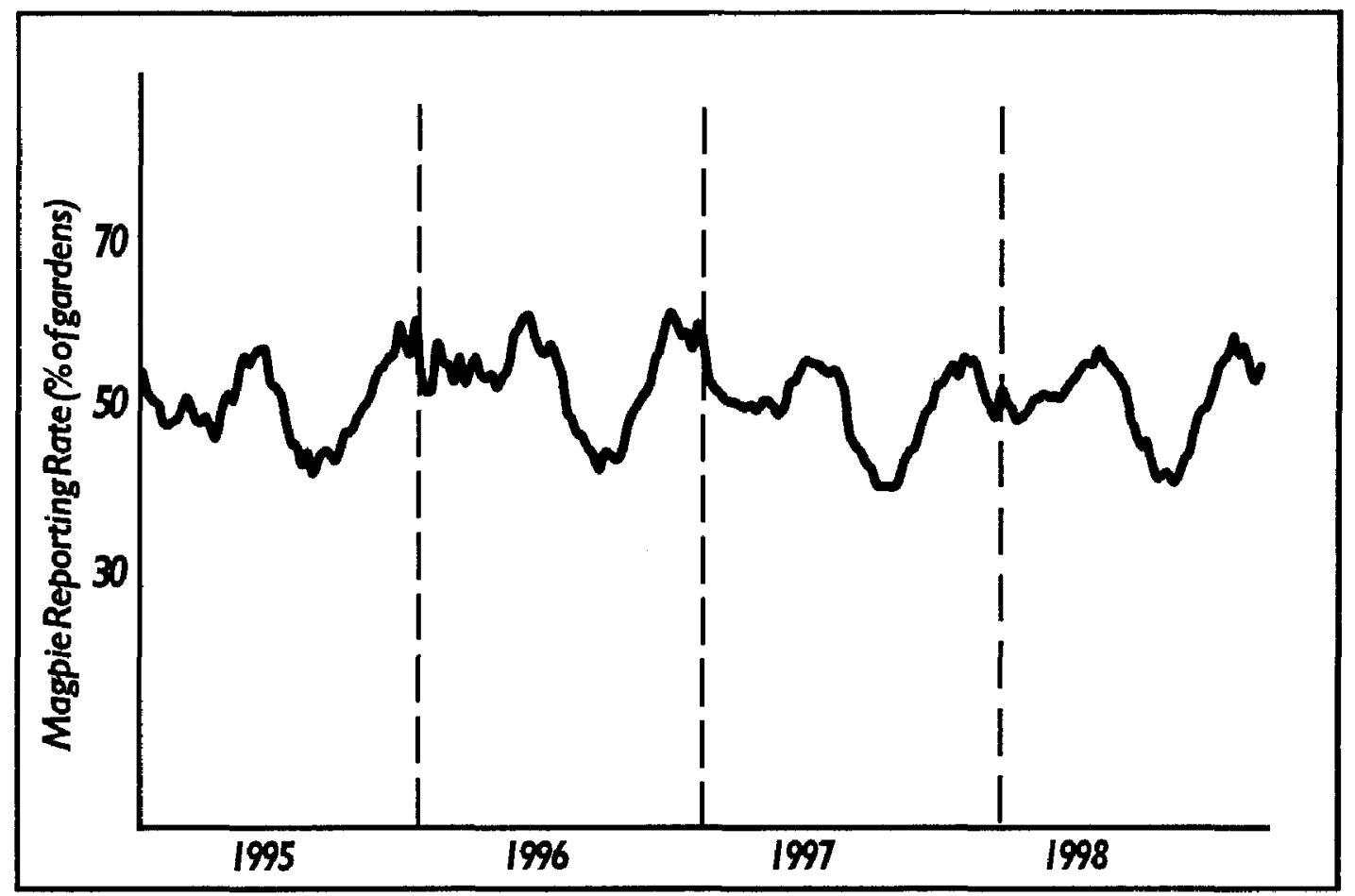

Figure 2. BTO/CJ Garden BirdWatch reporting rate plot for Black-billed Magpie Pica pica. Only around half of the volunteer bird recorders see this species in their gardens at any time of the year and there is no obvious short-term trend, contrary to reports in the popular media.

(Hamerstrom 1942). Much advanced work on bird behaviour has been performed in the ecologically exotic but eminently practical surroundings of university gardens (e.g. Davies 1992). Gardens are also excellent training grounds for ornithologists. The accessibility of the Paridae in gardens has enabled innumerable school and college students to perform simple educational investigations of feeding rates, breeding biology, dominance hierarchies, etc. For many bird ringers undergoing training, private gardens provide a copious supply of relatively tractable species and a supportive and controllable environment for their first attempts at unsupervised operation, that stressful but essential part of the transition from "apprentice" to "master" ringer.

\section{Garden birds in "the big picture"}

Garden ornithology can really work, inspiring professionals, engaging amateurs and providing unique data for conservation. British gardens already support species of serious conservation concern and their relative value as productive habitat is increasing as the wildlife gardening movement nudges them towards ecological integrity and sustainability and as other types of habitat deteriorate. They become more significant culturally, educationally and ornithologically as monitoring surveys and other simple, hands-on conservation-orientated garden projects become established, produce results and propagate. And furthermore they enable real people to participate in increasingly real conservation and to experience a genuine sense of the wild on their doorsteps. Because garden birds 
are not pets but ambassadors of the wild, touchstones of reality among the accelerating hyper-reality of modern life, fragile creatures which we cannot "own" or "manage" but to whom our personal actions in providing food, drink and nest sites can appear to make a real difference. This experience can be immensely empowering and engaging, perhaps more so than the disembodied, disempowering TV reportage of critically endangered species that seem beyond the help of the average person. To some activists, helping and monitoring garden birds may still appear relatively trivial in global conservation terms. But rather than compartmentalising conservation as exclusively for "experts", "activists" and other brands of "special people", garden conservation is inclusive and enabling. For those who take part it is utterly real. It is something they can see, touch and count. They can make a difference, and having proved to themselves that conservation really is possible, they will take an interest in the wider issues that affect "their" birds. Dennis Murphy wrote "If we cannot act as responsible stewards in our own backyards, the long-term prospects for biological diversity in the rest of this planet are grim indeed" (Murphy 1988) and to me, the most important indirect benefit of monitoring and helping garden birds is that it builds a sustainable, grassroots conservation constituency. Conservation will come rushing in once we all "get our thinking right", to paraphrase Chris Uhl (Uhl 1998), and the obvious starting point for this process is the land at our doorsteps. Gardens can be our training ground, not just for ornithologists but for a global conservation mentality. They are a springboard from which concepts of sustainable use and respect for biodiversity are launched into the wider community and they fully deserve recognition as part of what Thomas Birch has called "the continuum of sacred space", from cracks in the pavement to wilderness reserves, across which the diversity of life on this planet must be cherished (Birch 1995). At the British Trust for Ornithology we are finding that this approach really works. And apart from all this, garden birds are fascinating and beautiful birds! Becoming actively engaged in their wellbeing is enormous fun for everyone involved as well as of genuine conservation significance.

\section{Acknowledgements}

Grateful thanks to everyone who replied to my e-mail questionnaire: Belize Audubon Society; Lois Jammes, Armonia, Bolivia; Boris Barov, Bulgarian Society for the Protection of Birds; Ma. Del Coro Arizmendi, CIPAMEX, Mexico; Karel Stastny and Petra Malkova, Czech Republic; Bo Johansen, Dansk Ornitologisk Forening (DOF); Shriti Rajani, East African Natural History Society; Jasmina Muzinic, Institute for Ornithology, Croatia; Armando Gariboldi, LIPU; Aymeric Delporte, Ligue pour la Protection des Oiseaux (LPO); Lim Kim Keang \& Andrew Tay, Nature Society, Singapore (NSS); Ingar Jostein Øien, Norsk Ornitologisk Forening (NOF); Norita Scott-Pezet, Panama Audubon Society; Tony Saunders, Birds in Backyards, SNAG, Birds Australia; Sveriges Ornitologiska Forening (SOF); Kurt Bollmann, SVS - Birdlife Schweiz; Guillermo Egli, UNORCH, Chile; Titia Westermann, Vogelbescherming Nederland; Pete Leonard, Zambian Ornithological Society (ZOS). Thanks also to the Royal Society for the Protection of Birds (RSPB) and Project FeederWatch. Nigel Clark and Jeremy Greenwood provided helpful comments. My post is funded by BTO/CJ Garden BirdWatch participants' subscriptions and supported by CJ Wildbird Foods Ltd. 


\section{References}

Alexander, H.G. (1974) Seventy years of birdwatching. Calton (Staffordshire, U.K.): T. \& A.D. Poyser.

Birch, T. (1995) The incarceration of wildness. Pp. 339-355 in G. Sessions, ed. Deep ecology for the twenty-first century. Boston: Shambhala.

Bradbury, R.B. and Stoate, C. (in press) The ecology of yellowhammers on lowland farmland. In Lowland farmland birds - Proceedings of the 1999 BOU Spring Conference. London: British Ornithologists' Union.

Collar N.J., Crosby M.J. and Stattersfield A.J. (1994) Birds to watch 2: the world list of threatened birds. Cambridge, U.K.: BirdLife International.

Crick, H.Q.P., Baillie, S.R., Balmer, D.E.B., Bashford, R.I., Beaven, L.P., Dudley, C., Glue, D.E., Gregory, R.D., Marchant, J.H., Peach, W.J. and Wilson, A.M. (1998) Breeding birds in the wider countryside: their conservation status (1972-1996). Thetford: British Trust for Ornithology (Research Report 198).

Davies, N.B. (1992) Dunnock behaviour and social evolution. Oxford: Oxford University Press.

Gibbons, D.W., Avery, M.I., Baillie, S.R., Gregory, R.D., Kirby, J., Porter, R.F., Tucker, G.M. and Williams, G. (1996) Bird species of conservation concern in the United Kingdon, Channel Islands and Isle of Man: revising the Red Data List. RSPB Conserv. Rev. 10: $7-18$.

Hamerstrom, F. (1942) Dominance in winter flocks of chickadees. Wilson Bull. 54(1):32-42. Main, I.G. (1996) Seasonal movements of British Greenfinches Carduelis chloris. Bird Study 43: $240-252$

Mason, C.F. (1998) Habitats of the song thrush Turdus philomelos in a largely arable landscape. J. Zool., Lond. 244: 89-93

Murphy, D.D. (1988) Challenges to biodiversity in urban areas. Pp. 71-76 in E.O. Wilson, ed. Biodiversity. Washington, D.C.: National Academy Press.

Simms, E. (1978) British thrushes. London: Collins.

Uhl, C.F. (1998) Conservation biology in your own front yard. Conserv. Biol. 12: 1175-1177 Wells, J.V., Rosenberg, K.V., Dunn, E.H., Tessaglia, D.L. and Dhondt A.A. (1997) Feeder counts as indicators of spatial and temporal variation in winter abundance of resident birds. J. Field Ornithol. 69: 577-586

\section{ANDREW CANNON}

British Trust for Ornithology, The Nunnery, Thetford, IP 24 2PU, U.K.

e-mail: andrewc@bto.org 